Check for updates

Cite this: J. Mater. Chem. C, 2019, 7, 13966

Received 22nd August 2019, Accepted 23rd October 2019

DOI: $10.1039 / c 9 t c 04653 d$

rsc.li/materials-c

\title{
A single component white electroluminescent device fabricated from a metallo-organic terbium complex $\dagger$
}

\author{
Rashid IImi, (D) a Muhammad S. Khan, (D)*a Weidong Sun, ${ }^{b}$ Liang Zhou, (D)*b \\ Wai-Yeung Wong (D)*c and Paul R. Raithby (D)*d
}

\begin{abstract}
Two new mixed ligand complexes [Eu(tfac) $\left.)_{3}(\mathrm{DPEPO})\right]$ (Eu-1) and [Tb(tfac) $\left.)_{3}(\mathrm{DPEPO})\right]$ (Tb-2) incorporating trifluoroacetylacetone ( $\mathrm{Htfac}$ ) and bis(2-(diphenylphosphino)phenyl)ether oxide (DPEPO) were synthesized in gram-scale quantities and used as emitters to fabricate single- and double-EML (light-emitting layer) electroluminescence (EL) devices. The single-EML device with the structure: ITO/HAT-CN (6 nm)/HAT-CN (0.2 wt\%):TAPC (50 nm)/Eu-1 (1-6 wt\%): 26DCzPPy (10 nm)/Tm3PyP26PyB (50 nm)/LiF (1 nm)/Al (100 nm) showed light red (CIE, $x$ : 0.574; $y$ : 0.275) emission for the Eu-1 based EL devices due to the presence of a host emission with a brightness of $1274 \mathrm{~cd} \mathrm{~m}^{-2}$, current efficiency $\left(\eta_{\mathrm{c}}\right)$, power efficiency $\left(\eta_{\mathrm{p}}\right)$ and external quantum efficiency (EQE) of $0.58 \mathrm{~cd} \mathrm{~A}^{-1}, 0.68 \mathrm{~lm} \mathrm{~W}^{-1}$, and $0.70 \%$, respectively. The single-EML device for the Tb-2 complex with the same device structure displayed white-light emission. The optimized single-EML device of Tb-2 with $14.0 \mathrm{wt} \%$ doping concentration showed an impressive EL performance with brightness of $1637 \mathrm{~cd} \mathrm{~m}^{-2}, \eta_{\mathrm{c}} \approx 3.05 \mathrm{~cd} \mathrm{~A}^{-1}, \eta_{\mathrm{p}} \approx 2.80 \mathrm{~lm} \mathrm{~W}^{-1}$, EQE $\approx 1.4 \%, V_{\text {turn-on }} \approx 3.1 \mathrm{~V}$, respectively. This is the first report of single component white organic light emitting diode (W-OLED) fabricated from an organo$\mathrm{Tb}(\mathrm{III})$ complex. The $\mathrm{W}$-OLEDs show low turn-on voltages $\left(V_{\text {turn-on }}\right) \approx 3.1 \mathrm{~V}$ and are thus advantageous in lowering the power consumption of the OLED display.
\end{abstract}

\section{Introduction}

The development of W-OLEDs has gained momentum because of their potential to be used as alternatives to existing low efficient incandescent and fluorescent lights and as possible candidates for full-color displays. ${ }^{1}$ White light can be generated ${ }^{1 a}$ by (a) the monochromatic approach utilizing a single material capable of emitting across the entire visible spectrum $(400-700 \mathrm{~nm})$, (b) the bichromatic approach that needs two primary colors such as blue and yellow or orange and finally (c) the trichromatic approach that uses red, green and blue (RGB) emitting materials. In this respect a number of white electroluminescent (EL) devices employing

\footnotetext{
${ }^{a}$ Department of Chemistry, Sultan Qaboos University, P. O. Box 36, Al Khod 123, Sultanate of Oman. E-mail: msk@squ.edu.om

${ }^{b}$ State Key Laboratory of Rare Earth Resource Utilization, Changchun Institute of Applied Chemistry, Chinese Academy of Sciences, Renmin Street 5625,

Changchun 130022, People's Republic of China.E-mail: zhoul@ciac.ac.cn 'Department of Applied Biology and Chemical Technology,

The Hong Kong Polytechnic University, Hung Hom, Kowloon, Hong Kong. E-mail:wai-yeung.wong@polyu.edu.hk

${ }^{d}$ Department of Chemistry, University of Bath, Claverton Down, Bath BA2 7AY, UK. E-mail: p.r.raithby@bath.ac.uk

$\dagger$ Electronic supplementary information (ESI) available. CCDC 1942486 and 1942487. For ESI and crystallographic data in CIF or other electronic format see DOI: $10.1039 / \mathrm{c} 9 \mathrm{tc} 04653 \mathrm{~d}$
}

organic, polymeric and organometallic complexes have been utilized. ${ }^{1 e, 2}$ Organo-lanthanide complexes are interesting candidates because of their fascinating optical properties such as long luminescence lifetimes, ion-specific emission colors e.g. red for trivalent europium $[\mathrm{Eu}(\mathrm{III})]$ and green for trivalent terbium $[\mathrm{Tb}(\mathrm{III})]$, narrow line-like emission bands (Full Width at Half Maxima $(\mathrm{FWHM})<10 \mathrm{~nm})^{3} \beta$-diketones with organic chromophores have played a major role in lanthanide coordination chemistry because they can chelate the metal centers and as well as sensitize $\mathrm{Eu}$ (III) and $\mathrm{Tb}$ (III) emissions. Several interesting applications have been envisioned using this class of lanthanide coordination complexes such as single molecule magnets (SMMs), ${ }^{4}$ luminescent thermometers, ${ }^{5}$ sensors, ${ }^{6}$ and OLEDs. ${ }^{3 a, 7}$

The generation of W-OLEDs using organo-lanthanide complexes kick-started from the pioneering work of Kido et al., ${ }^{8}$ who fabricated W-OLEDs with multilayer device structures using red and green emitting ternary europium and terbium complexes $\left[\mathrm{Eu}(\mathrm{dbm})_{3} \mathrm{phen}\right]$ and $\left[\mathrm{Tb}(\mathrm{acac})_{3}\right.$ phen $]$ (acac $=$ acetylactonate, $\mathrm{dbm}=$ dibenzoylmethanate and phen $=1,10$-phenanthroline). Quirino et al. ${ }^{9}$ obtained white EL (CIE, $x=0.28 ; y=0.35$, with $20.5 \mathrm{~cd} \mathrm{~m}^{-2}$ of luminance) using bis-terpyridine bridged hetero-dinuclear complex of $\left[\mathrm{Eu}(\mathrm{btfa})_{3}\right]$ and $\left[\mathrm{Tb}(\mathrm{acac})_{3}\right]$ (btfa $=$ benzoyltrifluoroacetylacetonato). By following a similar approach, W-OLED of $\left[\mathrm{Eu}_{0.45} \mathrm{~Tb}_{0.55}(\mathrm{btfa})_{3}\left(4,4^{\prime}-\mathrm{bpy}\right)(\mathrm{EtOH})\right]$ with $(\mathrm{CIE}, x=0.353 ; y=0.316)$ 

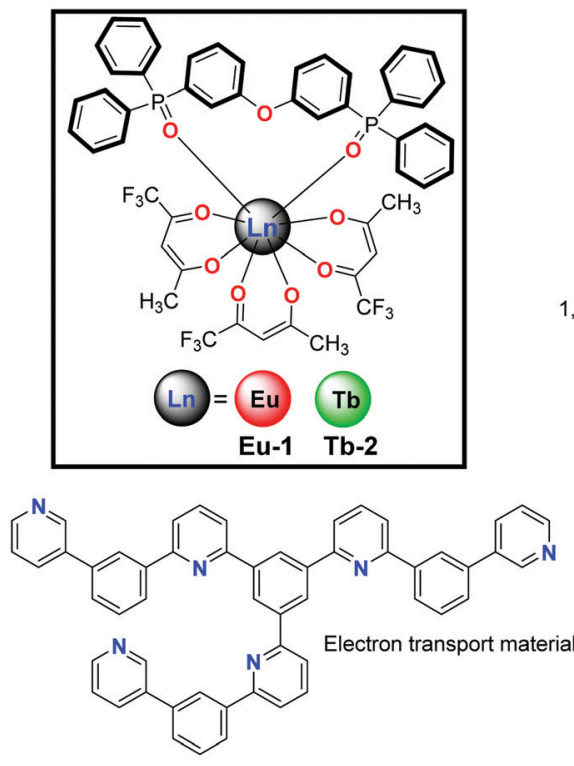

1,3,5-Tris(6-(3-(pyridin-3-yl)phenyl)pyridin-2-yl)benzene (Tm3PyP26PyB)

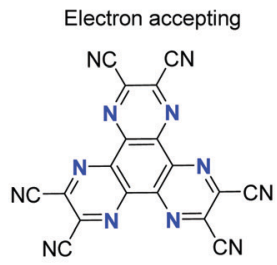

1,4,5,8,9,11-hexaazatriphenylene hexacarbonitrile (HAT-CN)

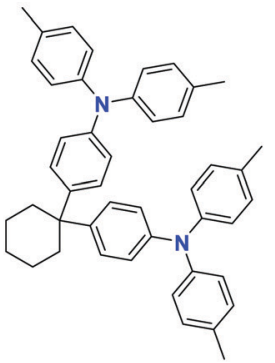

Di-[4-(N,N-ditolyl-amino)-phenyl]cyclohexane (TAPC)

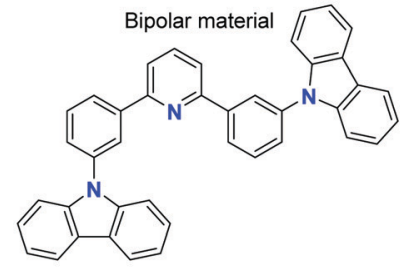

(26DCzPPy)

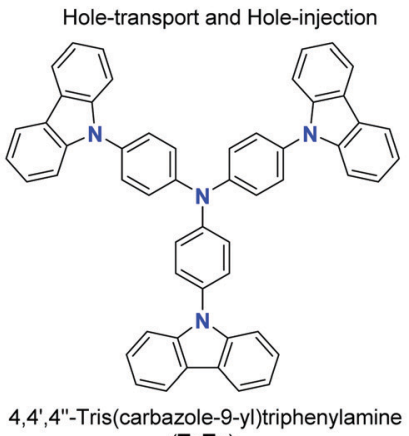

(TcTa)

Chart 1 Structures of new Eu-1 and Tb-2 complexes and chemicals used in EL device fabrication.

at $18 \mathrm{~V}\left(4,4^{\prime}\right.$-bpy $=4,4^{\prime}$-bipyridine $)$ has been reported. ${ }^{10}$ However, these multilayer devices using one or more emitting species make the fabrication of EL devices difficult and increase the manufacturing cost as well as the time taken to fabricate them, thereby limiting their real-life applications. An efficient way to circumvent these problems in W-OLEDs is to utilize a single-component emitter with tunable emission, which endows the device with important additional advantages such as good reproducibility and color stability. ${ }^{1 d}$ Based on this concept, Li et al., fabricated a W-OLED (CIE, $x=0.333 ; y=0.348$ ) from the dendritic complex [Eu(TCPD) ${ }_{3}$ phen] $($ TCPD = 1-[3,4,5-tris[4-(9H-carbazol-9-yl)butoxy]phenyl]-3-phenylpropane-1,3-dione) with a maximum brightness of $229 \mathrm{~cd} \mathrm{~m}^{-2}$ at voltage $20.5 \mathrm{~V} .{ }^{11}$ Similarly Law et al., ${ }^{12}$ fabricated a W-OLED from $\left[\mathrm{Eu}(\mathrm{tta})_{3} \mathrm{~L}\right](\mathrm{tta}=$ thenoyltrifluoroacetonate and $\mathrm{L}=2$-(3,5-dimethyl-2H-pyrrol-2-yl)-4-(3,5-dimethyl-3 $H$-pyrrol-2-yl)6-(4-(pentan-3-yl)phenyl)-1,3,5-triazine) with CIE, $x=0.337 ; y=$ 0.362 with $945.1 \mathrm{~cd} \mathrm{~m}^{-2}$ of luminance at $16 \mathrm{~V}$. Later, Zucchi et al., fabricated an exciplex generated W-OLED CIE, $x=0.35 ; y=0.33$ with maximum luminance of $19.7 \mathrm{~cd} \mathrm{~m}^{-2}$ at $7.6 \mathrm{~V}$ from the symmetrical homodinuclear $\left[\mathrm{Eu}_{2}(\mathrm{tta})_{6}\right] \mathrm{bpm}$ complex $(\mathrm{bpm}=$ 2,2'-bipyrimidine). ${ }^{13}$ Biju et al. ${ }^{14}$ have fabricated color-tunable OLED from the tetrakis $\mathrm{Eu}(\mathrm{III})$ complex $\mathrm{NBu}_{4}\left[\mathrm{Eu}\left(\mathrm{L}^{1}\right)_{4}\right]\left(\mathrm{L}^{1}=4-\left(4^{\prime}-\right.\right.$ carbazol-9-yl-biphenyl-4-yl)-1,1,1-trifluoro-4-oxo-but-2-en-2-ol). The single component device containing $\mathrm{NBu}_{4}\left[\mathrm{Eu}\left(\mathrm{L}^{1}\right)_{4}\right]$ in the emitting layers (EML) showed white EL (CIE, $x=0.337 ; y=0.328$ ) at $8 \mathrm{~V}$ with brightness of $1547 \mathrm{~cd} \mathrm{~m}^{-2}$ at $13.1 \mathrm{~V}$. Notably, the devices described above have utilized very high operating voltages to obtain the white-light. Only a handful of reports are available in the literature on the organo-lanthanide-based single component W-OLEDs. It is even more interesting that most of the reported W-OLEDs are based on $\mathrm{Eu}(\mathrm{III})$ complexes or $\mathrm{Eu}(\mathrm{III})$ and $\mathrm{Tb}$ (III) heterodinuclear complexes such as $\left[\mathrm{Eu}(\mathrm{btfa})_{3} \text { phenterpy } \mathrm{Tb}(\mathrm{acac})_{3}\right]^{9}$ and $\left[\mathrm{Eu}_{0.45} \mathrm{~Tb}_{0.55}(\mathrm{btfa})_{3}\left(4,4^{\prime}\right.\right.$-bpy)(EtOH $\left.)\right]{ }^{10}$ To the best of our knowledge, there is no report of single component $\mathrm{Tb}$ (III) based W-OLED.

Very recently ${ }^{3 a}$ we were able to see near white light (CIE, $x=0.257 ; y=0.337)$ emission from the $\left[\mathrm{Tb}(\mathrm{hfaa})_{3} \mathrm{Py}-\mathrm{Im}\right]$ complex [hfaa $=$ hexafluoroacetylacetone; Py-Im $=2-((2$ pyridyl)benzimidazole)]. The complex showed residual ligand emission which covers almost the entire visible region of the spectrum from 400-700 $\mathrm{nm}$. This was due to the incompatible triplet state $\left({ }^{3} \pi \pi^{*}\right)$ of Py-Im with the ${ }^{5} \mathrm{D}_{4}$ emitting level of $\mathrm{Tb}$ (III) with $\Delta E\left({ }^{3} \pi \pi^{*}-{ }^{5} \mathrm{D}_{4}\right) \approx 76 \mathrm{~cm}^{-1}$. In the present study we have synthesized two new ternary Ln(III) complexes $[\mathrm{Ln}(\mathrm{III})=\mathrm{Eu}(\mathrm{III})$ and $\mathrm{Tb}(\mathrm{III})]$ with hemi-fluorinated $\beta$-diketonate 'trifluoroacetylacetone (Htfac)' and bis(2-(diphenylphosphino)phenyl)ether oxide (DPEPO) as the neutral bidentate ligand to obtain $\left[\mathrm{Ln}(\mathrm{tfac})_{3}(\mathrm{DPEPO})\right]$ (Chart 1). The neutral and rigid chelate phosphine oxide 'DPEPO' is chosen because of its ability to coordinate to $\mathrm{Ln}$ (III) ions strongly and to transport electrons. ${ }^{15}$ Apart from this, the rigid structure of DPEPO is likely to increase the thermal stability of the complexes as well as facilitate the triplet energy transfer from ligands to the central Ln(III) ion. ${ }^{15}$ Furthermore, it also serves as a host material for the EML of OLEDs. ${ }^{16}$ The solid-state structures of $\left[\operatorname{Ln}(\mathrm{tfac})_{3}(\mathrm{DPEPO})\right][\mathrm{Ln}=\mathbf{E u - 1}$ and Tb-2 $]$ complexes were determined by X-ray single-crystal analysis. The photophysical properties of the complexes were evaluated in the solid-state and in solution by steady-state and time-resolved spectroscopy. Complexes Eu-1 and Tb-2 were further employed as an EML(s) to fabricate single- and double-layer OLEDs. For the first time $\mathrm{Tb}(\mathrm{III})$ based single component W-OLED (CIE at $10 \mathrm{~mA} \mathrm{~cm} \mathrm{~cm}^{-2}$, $x=0.293 ; y=0.351)$ is fabricated with an impressive maximum brightness of $(B) 1637 \mathrm{~cd} \mathrm{~m}^{-2}$ and a maximum power efficiency $\left(\eta_{\mathrm{p}}\right)$ $2.80 \mathrm{~lm} \mathrm{~W}^{-1}$ at a very low turn-on voltage $\left(V_{\text {turn-on }}\right)$ of $3.1 \mathrm{~V}$ compared to the reported single component W-OLEDs based on $\mathrm{Eu}(\mathrm{III})$ ion. The present work opens up a new avenue for 
utilizing $\mathrm{Tb}(\mathrm{III})$ complexes for high performance single component W-OLEDS.

\section{Experimental section: materials and instrumentation}

All chemicals were procured from commercial sources and were used without further purification unless otherwise specified. Metal chlorides of $\mathrm{Eu}$ (III) and $\mathrm{Tb}$ (III) were purchased from Strem Chemicals, Inc. Solvents used in the experiments were dried and distilled prior to use. Combustion analysis of the complexes Eu-1 and Tb-2 were performed on Euro EA-CHN Elemental Analyser. The Fourier transform infrared (FTIR) spectra of the solid complexes Eu-1 and Tb-2 were obtained using a Cary 630 FT-IR spectrometer in the attenuated total reflectance (ATR) mode. The electrospray ionization (ESI) mass spectra were obtained using a VG Autospec magnetic sector instrument. Thermal analyses of Eu-1 and Tb-2 were recorded on PerkinElmer TGA-4000 under a $\mathrm{N}_{2}$ atmosphere.

\subsection{Synthesis of $\left[\operatorname{Ln}(\operatorname{tfac})_{3}(\mathrm{DPEPO})\right][\mathrm{Ln}: \mathrm{Eu}$ and $\mathrm{Tb}]$}

$\left[\mathbf{L n}(\operatorname{tfac})_{3}(\mathrm{DPEPO})\right]$. Mixed ligand complexes [Ln(tfac $\left.)_{3}(\mathrm{DPEPO})\right]$ were synthesized by mixing an equimolar ethanolic solution of DPEPO $\approx 0.615 \mathrm{mmol}(0.351 \mathrm{~g}$ for Eu; $0.348 \mathrm{~g}$ for $\mathrm{Tb})$ dropwise with an ethanolic solution of $\left[\mathrm{Ln}(\mathrm{tfac})_{3}\left(\mathrm{H}_{2} \mathrm{O}\right)_{2}\right](0.615 \mathrm{mmol} ; 0.4 \mathrm{~g})$ (please see the details of synthesis and characterization in ESI $\dagger$ and their chemical structures in Chart S1). The reaction mixture was stirred overnight at RT and left for slow solvent evaporation for a week, after which period the solvent was decanted and the crystals were washed with ice-cold ethanol followed by hexane and dried in the air.

[Eu(tfac) $)_{3}\left(\right.$ DPEPO)] (Eu-1). Calculated for $\mathrm{C}_{51} \mathrm{H}_{40} \mathrm{EuF}_{9} \mathrm{O}_{9} \mathrm{P}_{2}$ : C, 51.83; H, 3.41, found C, 52.05; H, 3.00\%; ESI-MS ${ }^{+} \mathrm{m} / \mathrm{z}$ : $1028.90\left[\mathrm{Eu}(\mathrm{tfaa})_{2}(\mathrm{DPEPO})\right]^{+}$, (Fig. S1, ESI $\dagger$ ); FT-IR (solid; $\mathrm{cm}^{-1}$, Fig. $\mathrm{S} 2$, $\mathrm{ESI} \dagger)-\nu(\mathrm{C}=\mathrm{O}) \sim 1628(\mathrm{~s}) ; \nu(\mathrm{C}=\mathrm{C}) \sim 1532(\mathrm{~m}) ; \nu(\mathrm{P}=\mathrm{O}) \sim$ 1175(s); melting point $\left(T_{\mathrm{m}}\right): 223{ }^{\circ} \mathrm{C}$ as determined by the differential scanning calorimetry (DSC); decomposition temperature $\left(T_{\mathrm{d}}\right): 287^{\circ} \mathrm{C}$.

[Tb(tfac) $)_{3}($ DPEPO) $](\mathrm{Tb}-2)$. Calculated for $\mathrm{C}_{51} \mathrm{H}_{40} \mathrm{TbF}_{9} \mathrm{O}_{9} \mathrm{P}_{2}$ : $\mathrm{C}, 51.53 ; \mathrm{H}, 3.39$, found $\mathrm{C}, 51.59 ; \mathrm{H}, 3.02 \%$; ESI-MS ${ }^{+} \mathrm{m} / \mathrm{z}$ : $1035.00\left[\mathrm{~Tb}(\mathrm{tfaa})_{2}(\mathrm{DPEPO})\right]^{+}$(Fig. S3, ESI $\dagger$ ); FT-IR (solid; $\mathrm{cm}^{-1}$ ) $\nu(\mathrm{C}=\mathrm{O}) \sim 1629(\mathrm{~s}) ; \nu(\mathrm{C}=\mathrm{C}) \sim 1532(\mathrm{~m}) ; \nu(\mathrm{P}=\mathrm{O}) \sim 1174(\mathrm{~s})$ (Fig. S4, ESI $\dagger$ ); melting point $\left(T_{\mathrm{m}}\right): 217{ }^{\circ} \mathrm{C}$ as determined by DSC; $T_{\mathrm{d}}: 287^{\circ} \mathrm{C}$.

\subsection{Molecular structure determination by single-crystal X-ray crystallography}

Crystals of the Eu-1 and Tb-2 complexes for X-ray analysis were grown at room temperature by slow evaporation of concentrated ethanolic solution. X-ray intensity data were collected using $\phi$ and $\omega$ scans on an Oxford Diffraction Gemini A-Ultra diffractometer using monochromated Mo-K $_{\alpha}$ radiation $(\lambda=0.71073 \AA)$ at $150 \mathrm{~K}$. The structures were solved by direct methods (SIR-92) ${ }^{17}$ and refined with full-matrix least-squares, based on $F^{2}$ (ShelXL), ${ }^{18}$ within the OLEX-2 program suite. ${ }^{19}$
One of the $\mathrm{CF}_{3}$ groups in each structure was found to be disordered and was refined over two sites, with partial occupancies, restrained to unity. Hydrogen atoms were placed in idealized positions and refined using a riding model with isotropic displacement parameters refines with $U_{\text {eq }}(\mathrm{H})=1.2 U_{\text {eq }}(\mathrm{C})$ for the aromatic H-atoms and $1.5 U_{\text {eq }}(\mathrm{C})$ for the methyl H-atoms. The details of the measurements and structure refinements are presented in Table S1, ESI. $\dagger$

\subsection{Spectroscopic measurements, photophysical parameters and fabrication of EL devices}

Spectroscopic measurements of the free DPEPO ligand and the Eu-1 and Tb-2 complexes including optical absorption, excitation, emission spectra and decay profiles were obtained at room temperature and full details of the measurements have been reported previously. ${ }^{3 a, 20}$ Optical absorption spectra were obtained using Varian Cary 50 spectrophotometer while excitation, emission spectra and decay profiles were recorded on an Edinburgh FS5 fluorimeter. Important photophysical parameters such as JuddOfelt (J-O) parameters $\left(\Omega_{2}\right.$ and $\left.\Omega_{4}\right)$, radiative $\left(A_{\mathrm{R}}\right)$ and non-radiative $\left(A_{\mathrm{NR}}\right)$ decay rates, radiative lifetime $\left(\tau_{\mathrm{rad}}\right)$ and intrinsic quantum yield $\left(Q_{\mathrm{Eu}}^{\mathrm{Eu}}\right)$ were calculated using following eqn (1)-(7) and details are reported elsewhere. ${ }^{3 a, 20}$

$$
\begin{gathered}
\Omega_{\lambda}^{\text {exp }}=\frac{3 \hbar A_{\mathrm{R}}\left[{ }^{5} \mathrm{D}_{0} \rightarrow{ }^{7} \mathrm{~F}_{J}\right]}{32 e^{2} \pi^{3} \chi v\left[{ }^{5} \mathrm{D}_{0} \rightarrow{ }^{7} \mathrm{~F}_{J}\right]{ }^{3}\left|\left\langle{ }^{5} \mathrm{D}_{0} \| U(\lambda) \mid{ }^{7} \mathrm{~F}_{J}\right\rangle\right|^{2}} \\
A_{\mathrm{R}}=\sum_{J=0}^{4} A_{\mathrm{R}}\left[{ }^{5} \mathrm{D}_{0} \rightarrow{ }^{7} \mathrm{~F}_{J}\right] \\
A_{\mathrm{R}}\left[{ }^{5} \mathrm{D}_{0} \rightarrow{ }^{7} \mathrm{~F}_{J}\right]=\frac{v\left[{ }^{5} \mathrm{D}_{0} \rightarrow{ }^{7} \mathrm{~F}_{1}\right]}{v\left[{ }^{5} \mathrm{D}_{0} \rightarrow{ }^{7} \mathrm{~F}_{J}\right]} \\
\times \frac{A\left[{ }^{5} \mathrm{D}_{0} \rightarrow{ }^{7} \mathrm{~F}_{J}\right]}{A\left[{ }^{5} \mathrm{D}_{0} \rightarrow{ }^{7} \mathrm{~F}_{1}\right]} A_{\mathrm{R}}\left[{ }^{5} \mathrm{D}_{0} \rightarrow{ }^{7} \mathrm{~F}_{1}\right] \\
A_{\text {tot }}=\frac{1}{\tau_{\mathrm{obs}}}=A_{\mathrm{R}}+A_{\mathrm{NR}} \\
Q_{\mathrm{Eu}}^{\mathrm{Eu}}=\frac{\tau_{\text {obs }}}{\tau_{\mathrm{RAD}}}=\frac{A_{\mathrm{R}}}{A_{\mathrm{R}}+A_{\mathrm{NR}}} \\
\eta_{\text {sen }}=\frac{Q_{\mathrm{Eu}}^{\mathrm{L}}}{Q_{\mathrm{Eu}}^{\mathrm{Eu}}}
\end{gathered}
$$

The structure of the materials used in the fabrication process together with the complexes Eu-1 and Tb-2 are shown in Chart 1. All organic materials used in the fabrication were obtained commercially and used as received, while Eu-1 and Tb-2 were synthesized and purified in our laboratory (Chart 1). ITO coated glass with the sheet resistance of $10 \Omega \mathrm{sq}^{-1}$ was used as the anode substrate. Prior to film deposition, patterned ITO substrates were cleaned with detergent, rinsed in de-ionized water, and finally dried in an oven. All organic layers were deposited at a rate of $0.1 \mathrm{~nm} \mathrm{~s}^{-1}$ under high vacuum $\left(\leq 3.0 \times 10^{-5} \mathrm{~Pa}\right)$. 
The doped and co-doped EMLs were prepared by co-evaporating dopant(s) and host material from two or three individual sources, and the doping concentration was modulated by controlling the evaporation rate of dopant(s). $\mathrm{LiF}$ and $\mathrm{Al}$ were deposited in another vacuum chamber $\left(\leq 8.0 \times 10^{-5} \mathrm{~Pa}\right)$ at rates of 0.01 and $1.0 \mathrm{~nm} \mathrm{~s}^{-1}$, respectively, without being exposed to the atmosphere. The thicknesses of these deposited layers and the evaporation rate of individual materials were monitored in vacuum with quartz crystal monitors. A shadow mask was used to define the cathode and make eight emitting dots with the active area of $9 \mathrm{~mm}^{2}$ on each substrate. Current density-brightness-voltage $(J-B-V)$ characteristics were measured by using a programmable brightness light distribution characteristics measurement system C9920-11. The Photoluminescent (PL) and EL spectra were measured with a calibrated Hitachi F-7000 fluorescence spectrophotometer and an Ocean Optics spectrophotometer.

\section{Results and discussion}

\subsection{Synthesis, characterization and thermal analysis}

Gram scale syntheses of the Eu-1 and Tb-2 complexes shown in Chart 1 (inset) were accomplished in two steps. The binary hydrated complexes $\left[\mathrm{Ln}(\mathrm{tfac})_{3}\left(\mathrm{H}_{2} \mathrm{O}\right)_{2}\right][\mathrm{Ln}=\mathrm{Eu}(\mathrm{III})$ and $\mathrm{Tb}(\mathrm{III})]$ (please see $\mathrm{ESI} \dagger$ for synthesis) were first prepared and then reacted with the DPEPO ligand in ethanol (EtOH) at room temperature to obtain the final complexes. The synthesized Eu-1 and Tb-2 complexes were characterized by analytical and spectroscopic techniques while the structures were determined by single crystal X-ray diffraction (SC-XRD). The results of microanalysis and ESI-MS are consistent with Ln(III) to Htfac to DPEPO ratio of $1: 3: 1$ as shown in Chart 1 . The IR spectra of free DPEPO and Eu-1 and Tb-2 complexes are shown in Fig. S2 and S4, ESI. $\uparrow$ The complexes do not display any absorption between $3200-3600 \mathrm{~cm}^{-1}$ implying that DPEPO has successfully replaced the coordinated water molecules from the $\left[\mathrm{Ln}(\mathrm{tfac})_{3}\left(\mathrm{H}_{2} \mathrm{O}\right)_{2}\right]$. The IR spectra of both the complexes are almost similar and displayed two stretching absorption peaks $[\mathbf{E u}-1 ; \nu(\mathrm{C}=\mathrm{O}) \sim 1629(\mathrm{~s}) ; \nu(\mathrm{C}=\mathrm{C}) \sim$ 1532(m)] typical for $\beta$-diketonate chelated lanthanide complexes. Furthermore, $\mathrm{P}=\mathrm{O}$ stretching frequency at $1189 \mathrm{~cm}^{-1}$ of DPEPO is red shifted in the Eu-1 and Tb-2 complexes to $1174-1175 \mathrm{~cm}^{-1}$ confirming its coordination to the Ln(III) center. Thermal stability of the complexes is a very important factor since devices from low thermally stable (decomposition temperature, $T_{\mathrm{d}}$ ) complexes reduce the EL performance. The thermal stability of the new Eu-1 and Tb-2 complexes was determined by TGA and DSC under dinitrogen atmosphere and are shown in Fig. 1 and Fig. S5 and S6, ESI. $\dagger$ The thermogram of both complexes are nearly identical in shape and show two-step weight loss with almost the same $T_{\mathrm{d}} \approx 287{ }^{\circ} \mathrm{C}$. The high $T_{\mathrm{d}}$ facilitates the device fabrication. The complexes have higher $T_{\mathrm{d}}$ than $\left[\mathrm{Eu}(\mathrm{hfaa})_{3} \mathrm{DPEPO}\right]\left(T_{\mathrm{d}} \approx 228{ }^{\circ} \mathrm{C}\right)$ and marginally lower $T_{\mathrm{d}}$ than $\left[\mathrm{Eu}(\mathrm{btfa})_{3} \mathrm{DPEPO}\right]\left(T_{\mathrm{d}} \approx 320{ }^{\circ} \mathrm{C}\right)$ and [Eu(nta) ${ }_{3}$ DPEPO $\quad\left(T_{\mathrm{d}} \approx 318{ }^{\circ} \mathrm{C}\right)$ (nta $=3$-(2-naphthoyl)-1,1,1trifluoroacetonate). ${ }^{21}$ The DSC of the complexes displayed sharp endothermic peaks at $223{ }^{\circ} \mathrm{C}$ and $217{ }^{\circ} \mathrm{C}$ for Eu-1 and Tb-2, respectively, representing the $T_{\mathrm{m}}$ of the complexes (Fig. S5 and S6, ESI $\dagger$ ).

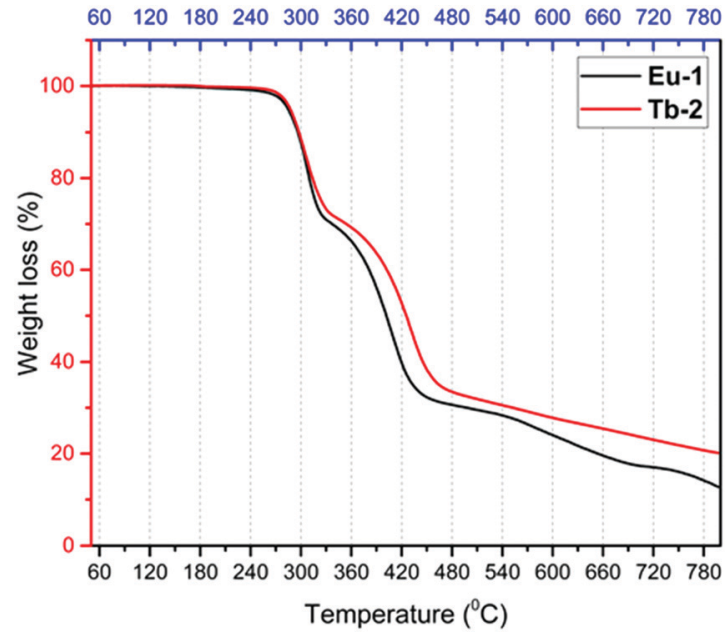

Fig. 1 TGA profiles of the Eu-1 (black) and Tb-2 (red) complexes under dinitrogen atmosphere.

The higher $T_{\mathrm{d}}$ and $T_{\mathrm{m}}$ arise presumably due to the rigid structure of the ancillary DPEPO ligand, making the complexes suitable for device fabrication by the thermal evaporation method. Furthermore, TGA profiles of Eu-1 and Tb-2 do not display any weight loss in the temperature region $60-180{ }^{\circ} \mathrm{C}$ and this suggests that the complexes do not have any water or solvent molecules, further attesting to the results of IR spectra.

\subsection{Molecular structure determination by single-crystal X-ray crystallography}

The crystal and molecular structures of $\left[\operatorname{Ln}(\mathrm{tfac})_{3}(\mathrm{DPEPO})\right]$ (Ln: $\operatorname{Eu}(\mathbf{E u - 1})$ and $\mathrm{Tb}(\mathbf{T b}-2)$ ) have been determined using single-crystal X-ray diffraction techniques. The two complexes are isomorphous and isostructural, crystallizing in the triclinic space group $P \overline{1}$ with one molecule in the asymmetric unit. Within each crystal structure the complexes are separated by

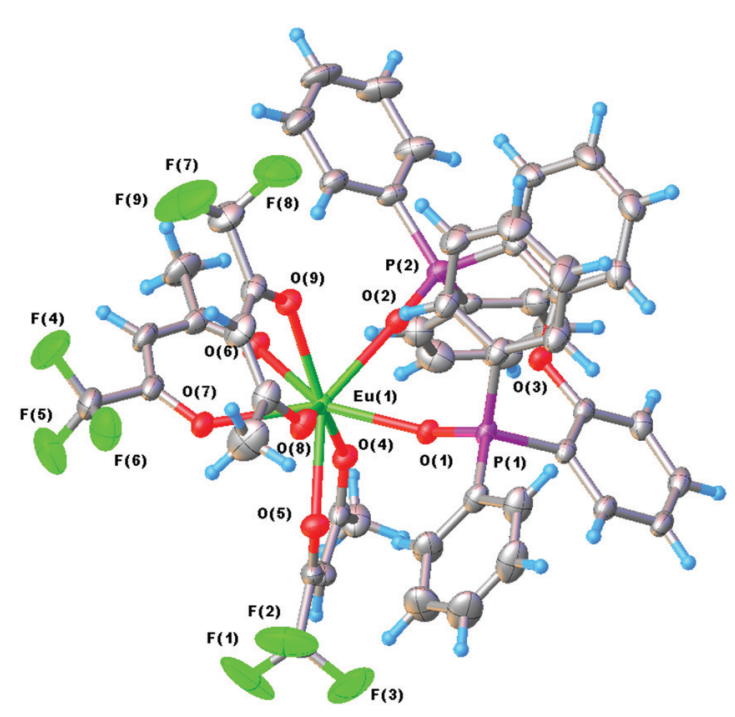

Fig. 2 The molecular structure of Eu-1 with displacement ellipsoids drawn at the $50 \%$ probability level. 
van der Waals distances and there are no significant short contacts between the molecules.

The $\mathrm{Eu}$ and $\mathrm{Tb}$ centers, in the two structures, are eight coordinate, bonded to three bidentate trifluoroacetate groups and a bidentate bis(2-(diphenylphosphino)phenyl)ether oxide ligand. The molecular structure of the Eu complex is shown in Fig. 2 (with that of the isostructural Tb complex in Fig. S7, ESI $\dagger$ ). Because of the chelating nature of the four ligands the coordination geometry around the metal is distorted from the possible limiting geometries, ${ }^{22}$ however it approximates most closely to a trigonal dodecahedron.

The three tfac ligands coordinate fairly symmetrically with Eu-O ranging from $2.373(2)$ to $2.437(2) \AA$ and $\mathrm{Tb}-\mathrm{O}$ from $2.347(2)$ to $2.410(2) \AA$, respectively. The chelating DPEPO ligand also coordinates symmetrically with the Eu-O bond lengths of 2.361(2) and 2.377(2) $\AA$ and those for Tb-O of 2.334(2) and 2.357(2) A. The slightly shorter distances for the Tb complex are consistent with the slight reduction of the $\mathrm{Tb}$ covalent radius compared to that of $\mathrm{Eu}$, consistent with the effect of the lanthanide contraction, in moving from left to right across the lanthanide series. The Eu-O(DPEPO) distances are similar to those in related eight coordinate Eu(III) phosphine oxide complexes $(2.345-2.446 \AA)^{23}$ as are the $\mathrm{Tb}-\mathrm{O}(\mathrm{DPEPO})$ bond lengths $(2.265-2.355 \AA) .{ }^{24}$ The other molecular parameters within the structures are unremarkable and full listing of the structural parameters for the two complexes are presented in Tables S2-S15, ESI. $\dagger$

\subsection{Photophysical properties of Eu-1 and Tb-2 complexes}

The optical absorption spectra of the free DPEPO ligand, Eu-1 and Tb-2 complexes were obtained in dichloromethane (DCM: $\left.\mathrm{CH}_{2} \mathrm{CL}_{2}\right)$ solution $\left(c \approx 5 \times 10^{-5} \mathrm{M}\right)$ at room temperature shown Fig. S8, ESI. $\dagger$ The free ligand displayed two major absorption peaks at $228 \mathrm{~nm}\left(\varepsilon \approx 48506 \mathrm{M}^{-1} \mathrm{~cm}^{-1}\right)$ and $290 \mathrm{~nm}\left(\varepsilon \approx 8863 \mathrm{M}^{-1} \mathrm{~cm}^{-1}\right)$. The spectra of Eu-1 and Tb-2 complexes are identical in shape and showed combined absorption peaks of both $\beta$-diketone and ancillary DPEPO ligand with $\varepsilon \approx 51314 \mathrm{M}^{-1} \mathrm{~cm}^{-1}$ for Eu-1 and $\varepsilon \approx 50270 \mathrm{M}^{-1} \mathrm{~cm}^{-1}$ for Tb-2 at $291 \mathrm{~nm}$, respectively. For an efficient sensitization of $\operatorname{Ln}(\mathrm{III})$ ion emissions in organo-lanthanide complexes, an appropriate energy difference $(\Delta E)$ between the triplet state of organic ligands and the emitting levels of $\mathrm{Ln}$ (III) ions must exist. For Eu(III) it should be higher than $2500 \mathrm{~cm}^{-125}$ while for $\mathrm{Tb}$ (III) it should be in the range of $2500-4000 \mathrm{~cm}^{-1} \cdot{ }^{26}$ In our present study there are two types of organic ligands with triplet states $\left({ }^{3} \pi \pi^{*}\right)$ at $22720 \mathrm{~cm}^{-1}$ and $24116 \mathrm{~cm}^{-1}$ for tfac and DPEPO, respectively. ${ }^{15,27}$ The ${ }^{3} \pi \pi^{*}$ of the organic ligands are well above the ${ }^{5} \mathrm{D}_{0}\left(17500 \mathrm{~cm}^{-1}\right)$ emitting state of $\mathrm{Eu}(\mathrm{III})$; with $\Delta E\left({ }^{3} \pi \pi^{*}-{ }^{5} \mathrm{D}_{0}\right) \approx\left(5220 \mathrm{~cm}^{-1}\right)_{\text {tfac }}$, an efficient ET can be observed. However, for the ${ }^{5} \mathrm{D}_{4}\left(20500 \mathrm{~cm}^{-1}\right)$ emitting state of $\mathrm{Tb}$ (III), this difference is $2220 \mathrm{~cm}^{-1}$ and perhaps could lead to back ET.

In view of this, we first analyzed the PL properties of the Eu-1 complex in the solid-state and in DCM solution, which are depicted in Fig. 3 and Fig. S9, ESI. $\dagger$ The excitation spectra in both cases were obtained by monitoring the ${ }^{5} \mathrm{D}_{0} \rightarrow{ }^{7} \mathrm{~F}_{2}$ emission transition and is composed of broad band that covers

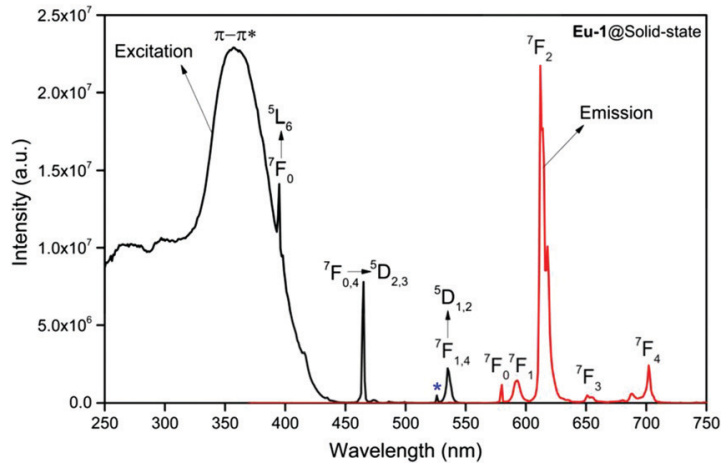

Fig. 3 Excitation and corrected emission spectra of Eu-1 in the solid state at $\mathrm{RT} .{ }^{7} \mathrm{~F}_{0} \rightarrow{ }^{5} \mathrm{D}_{1}$

the region between $250-400 \mathrm{~nm}$ with maxima at $359 \mathrm{~nm}$ and $340 \mathrm{~nm}$ for solid and DCM solution, respectively. The spectrum in the solid-state is also composed of $\mathrm{Eu}(\mathrm{III})$ centered excitation transitions i.e., intra-configurational $\mathrm{f}-\mathrm{f}$ transition and are assigned to the transition as shown in Fig. 3. Moreover, the intensity of the broad band is almost three times higher than ${ }^{7} \mathrm{~F}_{0} \rightarrow{ }^{5} \mathrm{D}_{2}\left(21505 \mathrm{~cm}^{-1} ; 465 \mathrm{~nm}\right)$ excitation transitions and can be taken as evidence in favor of the antenna mechanism. ${ }^{3 a, 20}$ The emission spectra of Eu-1 in the solid-state and in DCM solution recorded by exciting it at $\lambda_{\max }^{\mathrm{Ex}}$ displayed typical wellresolved $\mathrm{Eu}(\mathrm{III})$ emission transitions ${ }^{3 a, 20,28}$ corresponding to ${ }^{5} \mathrm{D}_{0} \rightarrow{ }^{7} \mathrm{~F}_{0,1,2,3,4}$ as shown in Fig. 3 and Fig. S9, ESI. $\dagger$ The relevant data such as peak positions and intensity relative to ${ }^{5} \mathrm{D}_{0} \rightarrow{ }^{7} \mathrm{~F}_{1}$ transition are gathered in Table S16, ESI. $\dagger$ In both cases, the spectra do not show any residual ligand-based emission suggesting an efficient intramolecular energy transfer from the ligands to $\mathrm{Eu}(\mathrm{III})$ center. $^{3 a, 20,28 a}$

A narrow $(F W H M \approx 7.84 \mathrm{~nm}$ and $10.21 \mathrm{~nm}$ for the solidstate and in DCM solution, respectively, Table 1) hypersensitive ${ }^{5} \mathrm{D}_{0} \rightarrow{ }^{7} \mathrm{~F}_{2}$ (accounting $\approx 79.50-82.41 \%$ of total integral intensity, Table S16, ESI $\dagger$ ) transition dominates the spectra, which is responsible for the bright red emission (CIE, $x=0.664 ; y=$ 0.324 for solid-state), Table S16 and Fig. S10 (ESI $\dagger$ ). Apart from this intense emission transition, the spectra displayed some weak transitions ${ }^{5} \mathrm{D}_{0} \rightarrow{ }^{7} \mathrm{~F}_{1},{ }^{5} \mathrm{D}_{0} \rightarrow{ }^{7} \mathrm{~F}_{3}$ and ${ }^{5} \mathrm{D}_{0} \rightarrow{ }^{7} \mathrm{~F}_{4}$ with total integral contribution of $16.39-19.82 \%$ towards the entire emission. The magnetic-dipole (MD) ${ }^{5} \mathrm{D}_{0} \rightarrow{ }^{7} \mathrm{~F}_{0}$ emission transition showed a well-resolved single peak (Fig. 3 and Fig. S9, ESI $\dagger$ ) with FWHM $\approx$ $(1.09 \mathrm{~nm})_{\text {solid-state }}$ and $(1.60 \mathrm{~nm})_{\mathrm{DCM}}$ Table 1 , suggesting a single chemical environment around the Eu(III) ion. ${ }^{3 a, 20,28 b}$ The steadystate emission spectra were used to obtain the $\Omega_{2}$ and $\Omega_{4}$ intensity parameters using eqn (1) above and the results obtained are shown in Table 1. For comparison excitation and emission spectra of $\left[\mathrm{Eu}(\mathrm{tfac})_{3}\left(\mathrm{H}_{2} \mathrm{O}\right)_{2}\right]$ were obtained under the same experimental condition and the results are shown in Fig. S11 and Tables S16 and S17 (ESI $\dagger$ ). Eu-1 shows a high value of $\Omega_{2} \approx 21.94 \times 10^{-20} \mathrm{~cm}^{2}$, indicative of lower symmetry with increased covalency between the $\mathrm{Eu}(\mathrm{III})$ ion and coordinated ligand ${ }^{29}$ compared to $\left[\mathrm{Eu}(\mathrm{tfac})_{3}\left(\mathrm{H}_{2} \mathrm{O}\right)_{2}\right]\left(\Omega_{2} \approx 18.60 \times 10^{-20} \mathrm{~cm}^{2}\right.$, Table S3, ESI $\dagger)$. The luminescence lifetime $\left(\tau_{\text {obs }}\right)$ of the ${ }^{5} \mathrm{D}_{0}$ excited state in both the solid-state and in solution were determined by 
Table 1 Photophysical properties of Eu-1 complex in the solid-state and in DCM at room temperature

\begin{tabular}{lllllllllll}
\hline & $\Omega_{2}{ }^{a}\left(\times 10^{-20} \mathrm{~cm}^{2}\right)$ & $\Omega_{4}{ }^{a}\left(\times 10^{-20} \mathrm{~cm}^{2}\right)$ & $\mathrm{FWHM}^{b}(\mathrm{~nm})$ & $\tau_{\mathrm{obs}}(\mu \mathrm{s})$ & $\tau_{\mathrm{rad}}{ }^{c}(\mu \mathrm{s})$ & $A_{\mathrm{R}}{ }^{d}\left(\mathrm{~s}^{-1}\right)$ & $A_{\mathrm{NR}}{ }^{e}\left(\mathrm{~s}^{-1}\right)$ & $Q_{\mathrm{Eu}}^{\mathrm{Eu}}(\%)$ & $Q_{\mathrm{Eu}}^{\mathrm{L}}(\%)$ & $\eta_{\mathrm{sen}}(\%)$ \\
\hline Solid-state & 21.94 & 6.06 & $1.09 ; 7.84$ & $960 \pm 2.96$ & 1227 & 814.81 & 226.86 & 78.22 & - & - \\
DCM & 24.29 & 8.15 & $1.60 ; 10.21$ & $987 \pm 1.06$ & 1276 & 783.41 & 229.76 & 77.32 & 55 & 70
\end{tabular}

${ }^{a}$ Calculated using eqn (1). ${ }^{b} \mathrm{FWHM}=$ Full Width at Half Maxima $\left({ }^{5} \mathrm{D}_{0} \rightarrow{ }^{7} \mathrm{~F}_{0} ;{ }^{5} \mathrm{D}_{0} \rightarrow{ }^{7} \mathrm{~F}_{2}\right) .{ }^{c}$ Calculated using eqn (5). ${ }^{d}$ Calculated using eqn (2) and (3). ${ }^{e}$ Calculated using eqn (4); $Q_{\mathrm{Eu}}^{\mathrm{Eu}}$ is calculated using eqn (6); $\eta_{\text {sen }}$ is calculated using eqn (7).

exciting the Eu-1 complex at $\lambda_{\max }^{\mathrm{Ex}}$ and fitting of the decay profiles (Fig. S12 and S13, ESI $\dagger$ ). The decay profiles could be fitted to mono-exponential function, $\tau_{\mathrm{obs}} \approx 960 \pm 2.96 \mu \mathrm{s}$ and $987 \pm 1.06 \mu \mathrm{s}$, respectively, for the solid-state and DCM solution (Table 1) and is consistent with single major emitting species and attests to the results of steady-state measurement where only one line is observed for the ${ }^{5} \mathrm{D}_{0} \rightarrow{ }^{7} \mathrm{~F}_{0}$ emission transition. The $\tau_{\text {obs }}$ for $\mathbf{E u}-\mathbf{1}$ is almost 2.5- and 3.88-fold longer than $\left[\mathrm{Eu}(\mathrm{tfac})_{3}\left(\mathrm{H}_{2} \mathrm{O}\right)_{2}\right]\left(\tau_{\mathrm{obs}} \approx 384 \mu \mathrm{s}\right.$ for the solid-state and $254 \mu$ s for DCM solution, Table S17 and Fig. S14, S15, ESI $\dagger$ ). This experimental fact could be related to the increase or decrease in the radiative $\left(A_{\mathrm{R}}\right)$ and non-radiative $\left(A_{\mathrm{NR}}\right)$ decay rates after coordination of the rigid ancillary DPEPO ligand. The values of $A_{\mathrm{R}}$ and $A_{\mathrm{NR}}$ are calculated using eqn (2)-(4) and the obtained data is shown in Table 1 and Table S17 (ESI $\dagger$ ). The 2.5- and 3.88-fold increase in $\tau_{\text {obs }}$ for Eu-1 is due to the reduction in $A_{\mathrm{NR}} \approx$ $226.28-229.76 \mathrm{~s}^{-1}$ from $1844.87-3305.38 \mathrm{~s}^{-1}$. The other parameters for Eu-1 in DCM solution such as radiative lifetime $\left(\tau_{\text {rad }}\right)$ of $1276 \mu \mathrm{s}$, intrinsic quantum yield $\left(Q_{\mathrm{Eu}}^{\mathrm{Eu}}\right)$, of $77.32 \%$, quantum yield $\left(Q_{\mathrm{Eu}}^{\mathrm{L}}\right)$ of $55.00 \%$ and sensitization efficiency $\left(\eta_{\text {sen }}\right)$ of $70 \%$ are calculated with the help of eqn (5)-(7) and are gathered in Table 1.

The PL excitation and emission spectra of Tb-2 complex in the solid-state and in DCM solution together with those of $\left[\mathrm{Tb}(\mathrm{tfac})_{3}\left(\mathrm{H}_{2} \mathrm{O}\right)_{2}\right]$ are shown in Fig. 4 and Fig. S16 (ESI $\left.\dagger\right)$. The excitation spectra of $\mathbf{T b}-\mathbf{2}$ show almost similar broad bands as observed in the case of Eu-2; however, the intensity is more than 7 times lower hinting at an inefficient ET from the organic ligand(s) to the central $\mathrm{Tb}(\mathrm{III})$ ion. The emission spectra shown in Fig. 4, display main emission transitions at $487 \mathrm{~nm}, 545 \mathrm{~nm}$, $586 \mathrm{~nm}, 623 \mathrm{~nm}$ (values are for Tb-2 complex in the solid-state)

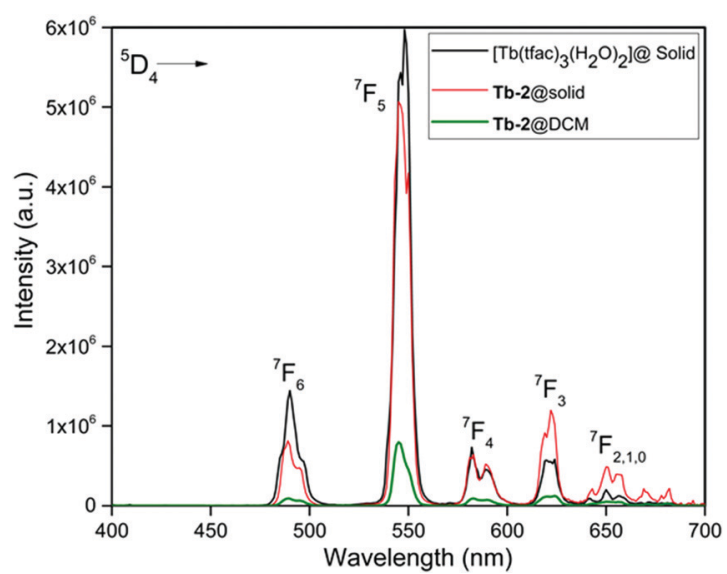

Fig. 4 Corrected emission spectra of Tb-2 complex in the solid-state and in DCM together with that of $\left[\mathrm{Tb}(\mathrm{tfac})_{3}\left(\mathrm{H}_{2} \mathrm{O}\right)_{2}\right]$ (solid-state) at room temperature. which are assigned to ${ }^{5} \mathrm{D}_{4} \rightarrow{ }^{7} \mathrm{~F}_{J}$ as shown in Fig. 4. The emission spectra are dominated by a ${ }^{5} \mathrm{D}_{4} \rightarrow{ }^{7} \mathrm{~F}_{5}$ transition; however, the intensity of this transition in the case of $\mathbf{T b}-\mathbf{2}$ (greenish-yellow emission, Fig. S17, ESI $\dagger$ ) in the solid-state is marginally lower compared to $\left[\mathrm{Tb}(\mathrm{tfac})_{3}\left(\mathrm{H}_{2} \mathrm{O}\right)_{2}\right]$ (green emission, Fig. S17, ESI $\dagger$ ) suggesting that the replacement of the water molecules by DPEPO has a detrimental effect on the emission intensity. Furthermore, the emission of Tb-2 in DCM solution decreased dramatically (6.32 times) compared to the emission in the solid-state. The $\tau_{\text {obs }}$ of ${ }^{5} \mathrm{D}_{4}$ were determined by the decay profiles of the Tb-2 and $\left[\mathrm{Tb}(\mathrm{tfac})_{3}\left(\mathrm{H}_{2} \mathrm{O}\right)_{2}\right]$ (Fig. S18-S20, ESI $\dagger$ ). The lifetime of Tb-2 $\left[\tau_{\mathrm{obs}} \approx(268.12 \mu \mathrm{s})_{\text {solid-state }}\right.$ and $\left.(24.32 \mu \mathrm{s})_{\mathrm{DCM}}\right]$ is shorter than that of $\left[\mathrm{Tb}(\mathrm{tfac})_{3}\left(\mathrm{H}_{2} \mathrm{O}\right)_{2}\right](384.45 \mu \mathrm{s})$. The $Q_{\mathrm{Tb}}^{\mathrm{L}}$ of $\mathbf{T b}-2$ in the solid-state and in DCM solution were determined using the calibrated integrating sphere method and the experimental details are provided in the ESI. $\dagger$ Despite the short lifetime of Tb-2, its $Q_{\mathrm{Tb}}^{\mathrm{L}}$ in the solid-state and in DCM solution is $53.00 \%$ and $48.00 \%$, respectively. A plausible explanation could be due to the electronic structure of $\mathrm{Tb}(\mathrm{III})$ that has many levels including a relatively low-lying $4 \mathrm{f}-5 \mathrm{~d}$ state, which can combine with the ligand wave functions. This explains the relatively short lifetime of $\mathbf{T b}-\mathbf{2} .^{30}$

\subsection{Electroluminescence performance and chromaticity of OLEDS}

To characterize EL properties of the Eu-1 and Tb-2 complexes, a series of single- and double- light-emitting layer devices with the following structure were fabricated;

Single EML device. ITO/HAT-CN $(6 \mathrm{~nm}) / \mathrm{HAT}-\mathrm{CN}(0.2 \mathrm{wt} \%)$ :TAPC $(50 \mathrm{~nm}) / \mathbf{E u}-\mathbf{1}$ or Tb-2 $(x$ wt\%): 26DCzPPy $(10 \mathrm{~nm}) / \mathrm{Tm} 3 \mathrm{PyP} 26 \mathrm{PyB}$ $(60 \mathrm{~nm}) / \mathrm{LiF}(1 \mathrm{~nm}) / \mathrm{Al}(100 \mathrm{~nm})$.

Double EML device. ITO/HAT-CN (6 nm)/HAT-CN (0.2 wt $\%)$ : TAPC $(50 \mathrm{~nm}) / \mathbf{E u}-\mathbf{1}$ or Tb-2 $(x$ wt\%): TcTa $(10 \mathrm{~nm}) / \mathbf{E u}-\mathbf{1}$ or $\mathbf{T b}-\mathbf{2}$ ( $x$ wt\%): 26DCzPPy $(10 \mathrm{~nm}) / \mathrm{Tm} 3$ PyP26PyB $(60 \mathrm{~nm}) / \mathrm{LiF}(1 \mathrm{~nm}) / \mathrm{Al}$ (100 nm).

The doping concentration for Eu-1 complex was modulated to be $1.0 \mathrm{wt} \%, 2.0 \mathrm{wt} \%, 3.0 \mathrm{wt} \%, 4.0 \mathrm{wt} \%, 5.0 \mathrm{wt} \%$, and $6.0 \mathrm{wt} \%$, respectively, while the doping concentration for $\mathbf{T b}-2$ complex was $8.0 \mathrm{wt} \%, 10.0 \mathrm{wt} \%, 12.0 \mathrm{wt} \%, 14.0 \mathrm{wt} \%$, and $16.0 \mathrm{wt} \%$, respectively. As the doping concentration increases, the evaporation temperature increases gradually from 131 to $137{ }^{\circ} \mathrm{C}$ and 138 to $146{ }^{\circ} \mathrm{C}$ for Eu-1 and Tb-2, respectively. The low thermal evaporation temperature of the complexes thus ensures negligible decomposition of the complexes during the thermal evaporation process $\left(T_{\mathrm{d}} \approx 287^{\circ} \mathrm{C}\right.$ as determined by the TGA, Fig. 1$)$.

For Eu-1, as listed in Table 2, single-EML devices displayed relatively higher EL performances compared with double-EMLs devices; however, the devices displayed color tunability from 
Table 2 Key properties of single and double EML with Eu-1 at different concentrations

\begin{tabular}{lllllll}
\hline Device & $V_{\text {turn-on }}(\mathrm{V})$ & $B^{a}\left(\mathrm{~cd} \mathrm{~m}^{-2}\right)$ & $\eta_{\mathrm{c}}{ }^{b}\left(\mathrm{~cd} \mathrm{~A}^{-1}\right)$ & $\eta_{\mathrm{p}}{ }^{c}\left(\mathrm{~lm} \mathrm{~W}^{-1}\right)$ & $\operatorname{EQE}^{d}(\%)$ & $\mathrm{CIE}_{x, y}{ }^{e}$ \\
\hline $1.0 \mathrm{wt} \%$ & $3.1[3.3]$ & $1286[1244]$ & $0.53[0.74]$ & $0.46[0.63]$ & $0.4[0.9]$ & $(0.375,0.196) ;[0.444,0.218]$ \\
$2.0 \mathrm{wt} \%$ & $3.3[3.3]$ & $1281[1011]$ & $0.67[0.90]$ & $0.57[0.78]$ & $0.5[1.1]$ & $(0.462,0.230) ;[0.533,0.253]$ \\
$3.0 \mathrm{wt} \%$ & $3.4[3.8]$ & $1358[1058]$ & $0.69[0.63]$ & $0.48[0.48]$ & $0.6[0.8]$ & $(0.511,0.257) ; 0.539,0.256]$ \\
$4.0 \mathrm{wt} \%$ & $3.4[3.6]$ & $1274[566]$ & $0.84[0.58]$ & $0.68[0.68]$ & $0.7[0.7]$ & $(0.526,0.257) ; 0.574,0.275]$ \\
$5.0 \mathrm{wt} \%$ & $3.5[3.7]$ & $1272[676]$ & $0.95[0.59]$ & $0.78[0.43]$ & $0.8[0.7]$ & $(0.560,0.273) ;[0.554,0.268]$ \\
$6.0 \mathrm{wt} \%$ & $3.8[3.6]$ & $980[565]$ & $0.51[0.69]$ & $0.41[0.53]$ & $0.4[0.9]$ & $(0.494,0.244) ;[0.557,0.257]$
\end{tabular}

The values in the square brackets are properties of double EML devices at different concentration. ${ }^{a}$ The data for maximum brightness $(B)$.

${ }^{b}$ Maximum current efficiency $\left(\eta_{\mathrm{c}}\right) .{ }^{c}$ Maximum power efficiency $\left(\eta_{\mathrm{p}}\right) .{ }^{d}$ Maximum external quantum efficiency (EQE). ${ }^{e} \mathrm{CIE}_{x, y}$ at $10 \mathrm{~mA} \mathrm{~cm}^{-2}$.
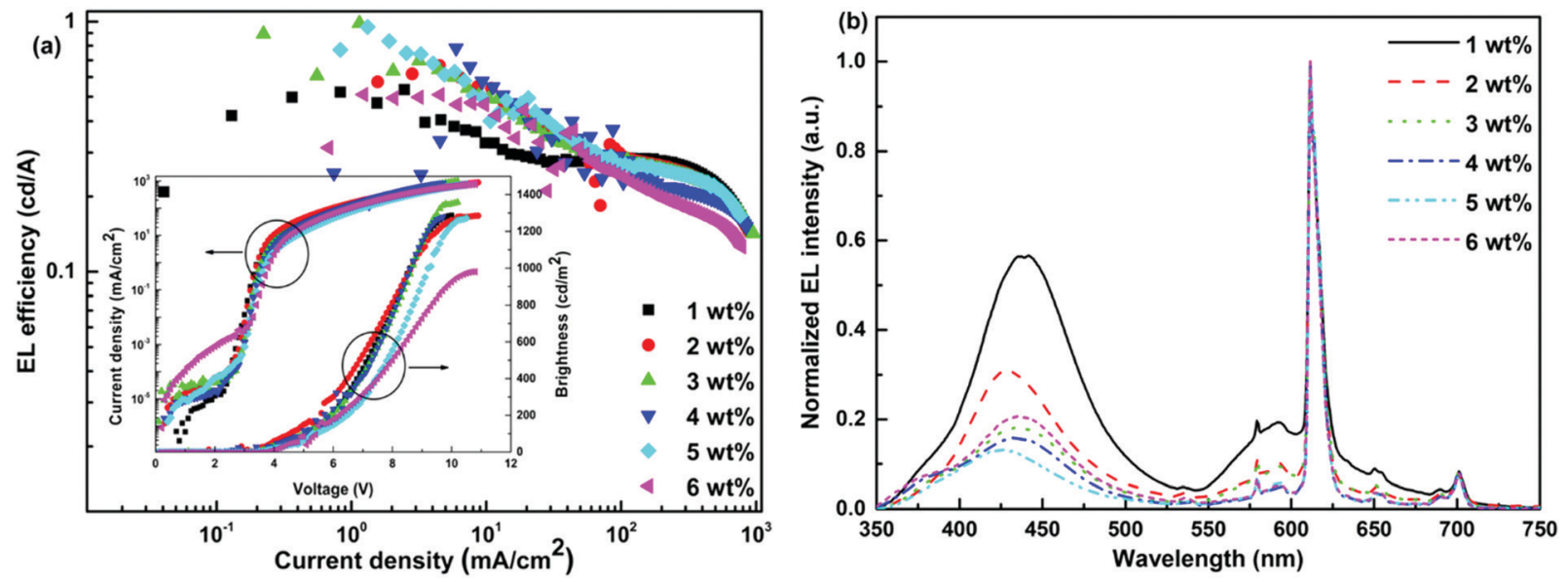

Fig. 5 (a) EL efficiency-current density characteristics of single-EML devices with Eu-1 at different doping concentrations. Inset: Current densitybrightness-voltage characteristics of the single-EML devices with Eu-1 at different doping concentrations. (b) Normalized EL spectra of the single-EML devices with Eu-1 at different doping concentrations operating at $10 \mathrm{~mA} \mathrm{~cm}{ }^{-2}$.

bluish-magenta (CIE, $x: 0.444 ; y: 0.218$ ) to light red (CIE, $x$ : $0.574 ; y: 0.275)$ as shown Table 2 and in Fig. S21 (ESI $\dagger$ ). The $5.0 \mathrm{wt} \%$ single-EML device obtained the highest current efficiency and power efficiency of $0.95 \mathrm{~cd} \mathrm{~A}^{-1}$ and $0.78 \mathrm{~lm} \mathrm{~W}^{-1}$, respectively, while the $3.0 \mathrm{wt} \%$ single-EML device obtained the highest brightness of $1358 \mathrm{~cd} \mathrm{~m}^{-2}$. Increasing the doping concentration of Eu-1 in both single- and double-EML devices increases the relative intensity of $\mathrm{Eu}(\mathrm{III})$ emission $(\approx 612 \mathrm{~nm})$ as shown in Fig. 5 and Fig. S22 (ESI $\dagger$ ). However, pure monochromatic Eu(III) emission was not realized due to the presence of host emission (exciplex emission originating from the recombination of accumulated holes on TAPC and accumulated electrons on 26DCzPPy molecules), though the $4.0 \mathrm{wt} \%$ single-EML device displays light red (CIE, $x: 0.574 ; y: 0.275$ )

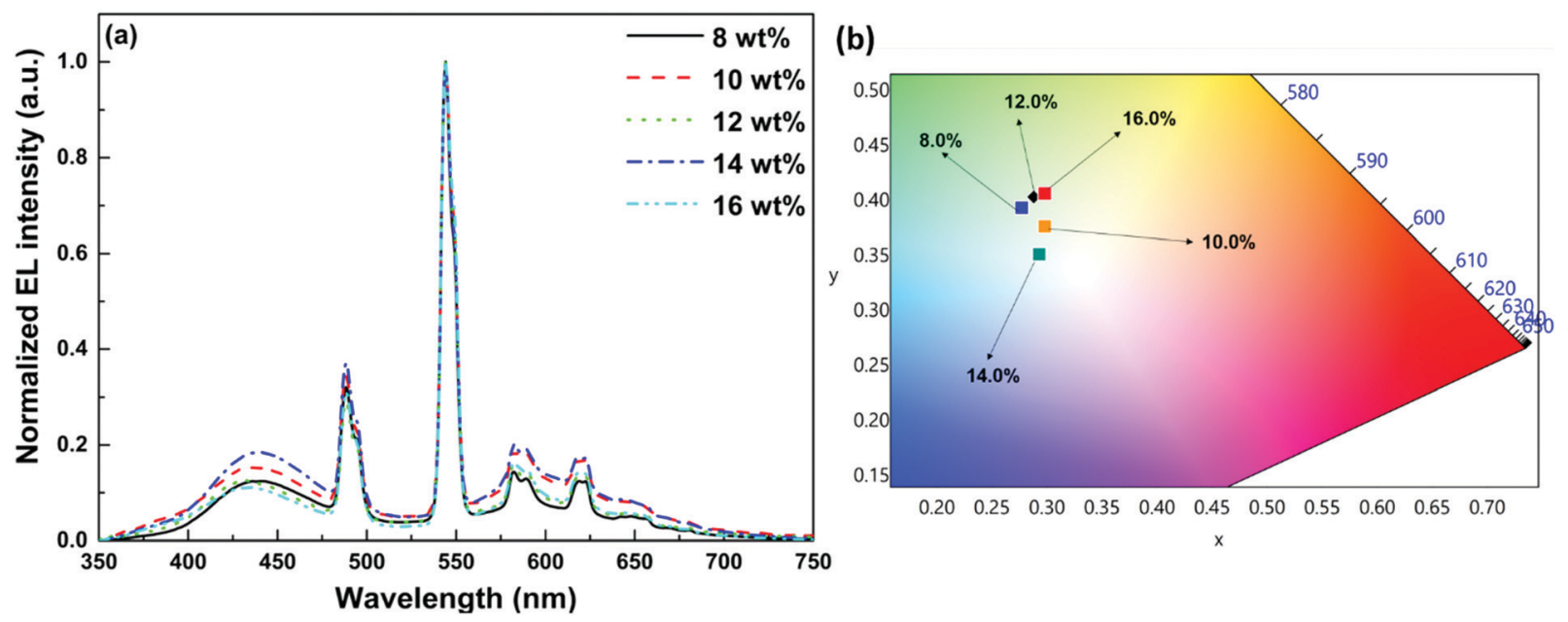

Fig. 6 (a) Normalized EL spectra of the single-EML devices with Tb-2 at different doping concentrations operating at $10 \mathrm{~mA} \mathrm{~cm}{ }^{-2}$. (b) $A \mathrm{magnified}$ view of the CIE color coordinates at $10 \mathrm{~mA} \mathrm{~cm} \mathrm{~cm}^{-2}$ of single-EML devices with different doping concentration of Tb-2 complex. 


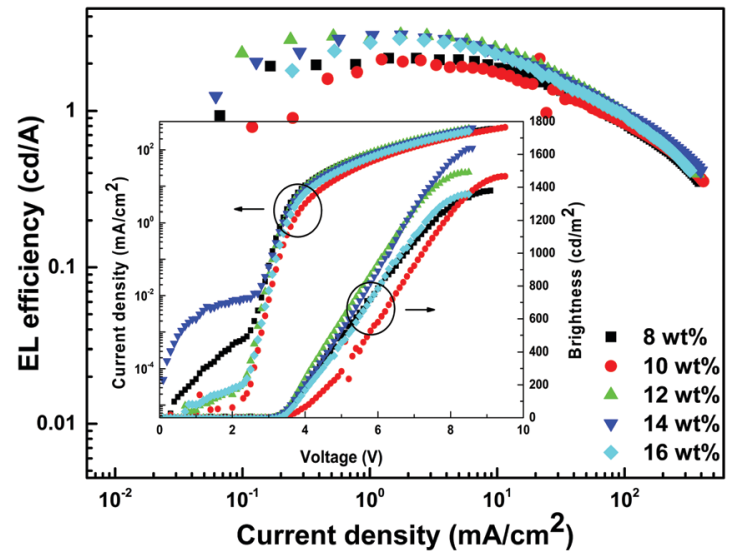

Fig. 7 EL efficiency-current density characteristics of the single-EMLs devices with $\mathbf{T b}-\mathbf{2}$ at different doping concentrations. Inset: Current density-brightness-voltage characteristics of the single-EML devices with Tb-2 at different doping concentrations.

emission with brightness of $1274 \mathrm{~cd} \mathrm{~m}^{-2}$, current efficiency and power efficiency of $0.58 \mathrm{~cd} \mathrm{~A}^{-1}$ and $0.68 \mathrm{~lm} \mathrm{~W}^{-1}$, respectively. This could be attributed to the inefficient carriers trapping or the incomplete ET. It is important to emphasize that these EL performances are remarkably at very low $V_{\text {turn-on }} \approx 3.1-3.8 \mathrm{~V}$, and therefore, advantageous in lowering the power consumption of the OLED display, which is an important issue. The EL performances of the devices compare well with the similar type of $\mathrm{Eu}(\mathrm{III})$ complexes with $\mathrm{P}=\mathrm{O}$ ligands. ${ }^{15,31}$

In order to establish proof of concept that we should be able to generate white-light from Tb-2 complex in the EL devices, we have used Tb-2 complex as EML to fabricate single- as well as double-EMLs devices with the same structure as Eu-1 but different doping concentrations. Normalized EL spectra of single- and double-EML devices are shown in Fig. 6a and Fig. S23 (ESI + ). The emitting color of the double-EML devices displayed light cyan (CIE, $x: 0.262 ; y: 0.408$ ) to celeste (CIE, $x: 0.252 ; y: 0.456)$ as shown in Fig. S24 (ESI $\dagger$ ). The EL efficiency and current density curves together with the voltage $(V)$-brightness and current density curves as an inset is shown Fig. 7 and Fig. S25 (ESI $\dagger$ ). The detailed performances of the single- and double-EML devices are shown in Table 3 and Table S18, ESI. $\dagger$ As shown in Table 3 and Table S18 (ESI $\dagger$ ), single-EML devices displayed relatively higher brightness while double-EMLs devices displayed relatively higher EL efficiencies. The double-EML device with $12.0 \mathrm{wt} \%$ obtained a brightness of $1341 \mathrm{~cd} \mathrm{~m}^{-2}, \eta_{\mathrm{c}} \approx 11.96 \mathrm{~cd} \mathrm{~A}^{-1}$, and $\eta_{\mathrm{p}} \approx 11.02 \mathrm{~lm} \mathrm{~W}^{-1}$, respectively at low $V_{\text {turn-on }} \approx 3.3 \mathrm{~V}$. Interestingly, as expected the single-EML devices with different doping concentration of Tb-2 complex displayed white-light emission with CIE color coordinates as shown in Fig. 6b and Table 3 at with low $V_{\text {turn-on }} \approx 2.9-3.3 \mathrm{~V}$. The optimized single-EML device with $14.0 \mathrm{wt} \%$ doping concentration showed an impressive EL performances with the brightness of $1637 \mathrm{~cd} \mathrm{~m}^{-2}, \eta_{\mathrm{c}} \approx 3.05 \mathrm{~cd} \mathrm{~A}^{-1}$, $\eta_{\mathrm{p}} \approx 2.80 \mathrm{~lm} \mathrm{~W} \mathrm{~W}^{-1}$ and $V_{\text {turn-on }} \approx 3.1 \mathrm{~V}$, respectively. To the best of our knowledge a single-component W-OLED with a $\mathrm{Tb}(\mathrm{III})$ complex has not been reported previously.

\section{Conclusion}

In summary, two new complexes $\left[\mathrm{Eu}(\mathrm{tfac})_{3}(\mathrm{DPEPO})\right]$ and $\left[\mathrm{Tb}(\mathrm{tfac})_{3}(\mathrm{DPEPO})\right]$ have been successfully synthesized on the gram scale and characterized. The EL devices fabricated from the new Eu-1 and Tb-2 complexes as EML displayed good performance. Double EML devices with Eu-1 as an EML displayed color-tunability from bluish-pink (CIE, $x: 0.375 ; y$ : 0.196) to light pinkish-red (CIE, $x: 0.574 ; y: 0.275$ ). Single EML device with $3.0 \mathrm{wt} \%$ doping concentration displayed a brightness of $1358 \mathrm{~cd} \mathrm{~m}^{-2}$, current efficiency and power efficiency of $0.69 \mathrm{~cd} \mathrm{~A}^{-1}$ and $0.48 \mathrm{~lm} \mathrm{~W}^{-1}$, respectively, at very low $V_{\text {turn-on }} \approx 3.4 \mathrm{~V}$. Single EML device with $14.0 \mathrm{wt} \%$ of Tb-2 exhibited impressive white EL (CIE, $x: 0.293 ; y: 0.351$ ) with brightness of $1637 \mathrm{~cd} \mathrm{~m}^{-2}, \eta_{\mathrm{c}}, \eta_{\mathrm{p}}$ and EQE of $3.05 \mathrm{~cd} \mathrm{~A}^{-1}, 2.80 \mathrm{~lm} \mathrm{~W}^{-1}, 1.4 \%$, respectively, at very low $V_{\text {turn-on }} \approx 3.1 \mathrm{~V}$. To the best of our knowledge, this is the first report of a single component $\mathrm{Tb}$ (III) based W-OLED with impressive

Table 3 Key properties of single-EML with Tb-1 at different concentrations

\begin{tabular}{|c|c|c|c|c|c|c|}
\hline Device & $V_{\text {turn-on }}(\mathrm{V})$ & $B^{\mathrm{a}}\left(\mathrm{cd} \mathrm{m}^{-2}\right)$ & $\eta_{\mathrm{c}}^{\mathrm{b}}\left(\mathrm{cd} \mathrm{A}^{-1}\right)$ & $\eta_{\mathrm{p}}^{\mathrm{c}}\left(\operatorname{lm~\mathrm {W}^{-1})}\right.$ & $\operatorname{EQE}^{\mathrm{d}}(\%)$ & $\mathrm{CIE}_{x, y}{ }^{\mathrm{e}}$ \\
\hline $10.0 \mathrm{wt} \%$ & 3.3 & 1466 & 2.09 & 1.70 & 0.9 & $(0.298,0.376)$ \\
\hline $12.0 \mathrm{wt} \%$ & 3.2 & 1491 & 3.06 & 2.83 & 1.2 & $(0.288,0.403)$ \\
\hline $16.0 \mathrm{wt} \%$ & 3.3 & 1357 & 2.89 & 2.53 & 1.2 & $(0.298,0.406)$ \\
\hline
\end{tabular}

The superscripts have the same meaning as discussed in Table 2.

Table 4 A comparative EL characteristic performance of single component W-OLEDs

\begin{tabular}{llllll}
\hline Complex & $B^{\mathrm{a}}\left(\mathrm{cd} \mathrm{m}^{-2}\right)$ & $V_{\text {turn-on }}(\mathrm{V})$ & $\eta_{\mathrm{p}}{ }^{\mathrm{c}}\left(\mathrm{lm} \mathrm{W}^{-1}\right)$ & CIE $^{\mathrm{e}}$ & Ref. \\
\hline Tb-2 & 1637 & 3.1 & 2.80 & $0.293 ; 0.351$ \\
{$\left[\mathrm{Eu}(\mathrm{TCPD})_{3}\right.$ Phen $]$} & 229 & 20.5 & $0.2(10.5 \mathrm{~V})$ & $0.333 ; 0.348$ \\
{$\left[\mathrm{Eu}(\mathrm{tta})_{3} \mathrm{~L}\right]$} & 945.1 & 16 & - & $0.337 ; 0.362$ \\
{$\left[\mathrm{Eu}_{2}(\mathrm{tta})_{6}\right] \mathrm{bpm}$} & 19.7 & 7.6 & - & $0.350 ; 0.330$ \\
$\mathrm{NBu}_{4}\left[\mathrm{Eu}\left(\mathrm{L}^{1}\right)_{4}\right]$ & $1547(13.1 \mathrm{~V})$ & & $2.53(6.4 \mathrm{~V})$ & $0.337 ; 0.328(8 \mathrm{~V})$
\end{tabular}

Superscripts a, c an e have the same meanings as in Table 2. 
EL performances compared to $\mathrm{Eu}(\mathrm{III})$ based single component W-OLEDs (Table 4). Presently, synthesis of stable organolanthanide complexes containing a range of $\mathrm{P}=\mathrm{O}$ and $\mathrm{N}, \mathrm{N}$ donors ligands to improve the EL properties are in progress in our laboratory. Some of the preliminary results are encouraging. Moreover, we are also exploring other organo- $\mathrm{Tb}$ (III) complexes to achieve high performance single component W-OLEDs.

\section{Conflicts of interest}

The authors declare no conflicting interests.

\section{Acknowledgements}

MSK acknowledges His Majesty's Trust Fund for Strategic Research (Grant No. SR/SQU/SCI/CHEM/16/02) for funding. RI thanks HM's Trust Fund for a post-doctoral fellowship. PRR is grateful to the Engineering and Physical Sciences Research Council (EPSRC, UK) for funding (EP/K004956/1). WYW thanks the Hong Kong Polytechnic University (1-ZE1C) and the Endowed Professorship in Energy from Ms Clarea Au (847S) for the financial support. LZ is grateful to the financial aid from National Natural Science Foundation of China (21771172), Youth Innovation Promotion Association of Chinese Academy of Sciences (2013150).

\section{References}

1 (a) M. Pan, W.-M. Liao, S.-Y. Yin, S.-S. Sun and C.-Y. Su, Chem. Rev., 2018, 118, 8889-8935; (b) S. SeethaLekshmi, A. R. Ramya, M. L. P. Reddy and S. Varughese, J. Photochem. Photobiol., C, 2017, 33, 109-131; (c) G. M. C. K. Anne and M. Klaus, Adv. Mater., 2011, 23, 233-248; (d) G. M. Farinola and R. Ragni, Chem. Soc. Rev., 2011, 40, 3467-3482; (e) L. Ying, C.-L. Ho, H. Wu, Y. Cao and W.-Y. Wong, Adv. Mater., 2014, 26, 2459-2473.

2 (a) X. Ma, J. Li, C. Lin, G. Chai, Y. Xie, W. Huang, D. Wu and W. Y. Wong, Phys. Chem. Chem. Phys., 2019, 21, 14728-14733; (b) C. L. Ho and W. Y. Wong, Top. Curr. Chem., 2016, 374, 64; (c) A. Zhang, B. Wang, Q. Yan, Y. Wang, J. Jia, H. Jia, B. Xu and W.-Y. Wong, Opt. Mater. Express, 2018, 8, 3635-3652; (d) Y. He, L. Liu, G. Fu, W. Li, X. Lü, H. He and W.-Y. Wong, J. Mater. Chem. C, 2019, 7, 4800-4807.

3 (a) R. Ilmi, M. S. Khan, Z. Li, L. Zhou, W.-Y. Wong, F. Marken and P. R. Raithby, Inorg. Chem., 2019, 58, 8316-8331; (b) J.-C. G. Bünzli, in Handbook on the Physics and Chemistry of Rare Earths, ed. J.-C. G. Bünzli and V. K. Pecharsky, Elsevier, 2016, vol. 50, pp. 141-176.

4 (a) X. Yao, P. Yan, G. An, Y. Li, W. Li and G. Li, Dalton Trans., 2018, 47, 3976-3984; (b) J. Long, Y. Guari, R. A. S. Ferreira, L. D. Carlos and J. Larionova, Coord. Chem. Rev., 2018, 363, 57-70.

5 (a) Y. Yang, H. Huang, Y. Wang, F. Qiu, Y. Feng, X. Song, X. Tang, G. Zhang and W. Liu, Dalton Trans., 2018, 47,
13384-13390; (b) J. Rocha, C. D. S. Brites and L. D. Carlos, Chem. - Eur. J., 2016, 22, 14782-14795; (c) C. D. S. Brites, A. Millán and L. D. Carlos, in Handbook on the Physics and Chemistry of Rare Earths, ed. B. Jean-Claude and P. Vitalij, Elsevier, 2016, vol. 49, pp. 339-427.

6 (a) W.-H. Huang, J. Ren, Y.-H. Yang, X.-M. Li, Q. Wang, N. Jiang, J.-Q. Yu, F. Wang and J. Zhang, Inorg. Chem., 2019, 58, 1481-1491; (b) J. A. Smith, M. A. Singh-Wilmot, K. P. Carter, C. L. Cahill and J. A. Ridenour, Cryst. Growth Des., 2018, 19, 305-319.

7 (a) H. Xu, K. Yin and W. Huang, Chem. - Eur. J., 2007, 13, 10281-10293; (b) G. Yu, F. Ding, H. Wei, Z. Zhao, Z. Liu, Z. Bian, L. Xiao and C. Huang, J. Mater. Chem. C, 2016, 4, 121-125; (c) J. Wang, C. Han, G. Xie, Y. Wei, Q. Xue, P. Yan and H. Xu, Chem. - Eur. J., 2014, 20, 11137-11148.

8 J. Kido, W. Ikeda, M. Kimura and K. Nagai, Jpn. J. Appl. Phys., 1996, 35, L394-L396.

9 W. G. Quirino, C. Legnani, M. Cremona, P. P. Lima, S. A. Junior and O. L. Malta, Thin Solid Films, 2006, 494, 23-27.

10 P. P. Lima, F. A. A. Paz, C. D. S. Brites, W. G. Quirino, C. Legnani, M. Costa e Silva, R. A. S. Ferreira, S. A. Junior, O. L. Malta, M. Cremona and L. D. Carlos, Org. Electron., 2014, 15, 798-808.

11 S. Li, G. Zhong, W. Zhu, F. Li, J. Pan, W. Huang and H. Tian, J. Mater. Chem., 2005, 15, 3221-3228.

12 G.-L. Law, K.-L. Wong, H.-L. Tam, K.-W. Cheah and W.-T. Wong, Inorg. Chem., 2009, 48, 10492-10494.

13 G. Zucchi, T. Jeon, D. Tondelier, D. Aldakov, P. Thuery, M. Ephritikhine and B. Geffroy, J. Mater. Chem., 2010, 20, 2114-2120.

14 S. Biju, L.-J. Xu, C.-Z. Sun and Z.-N. Chen, J. Mater. Chem. C, 2015, 3, 5775-5782.

15 H. Xu, L.-H. Wang, X.-H. Zhu, K. Yin, G.-Y. Zhong, X.-Y. Hou and W. Huang, J. Phys. Chem. B, 2006, 110, 3023-3029.

16 (a) E. Busby, J. Xia, Q. Wu, J. Z. Low, R. Song, J. R. Miller, X. Y. Zhu, L. M. Campos and M. Y. Sfeir, Nat. Mater., 2015, 14, 426; (b) Q. Zhang, B. Li, S. Huang, H. Nomura, H. Tanaka and C. Adachi, Nat. Photonics, 2014, 8, 326.

17 M. C. Burla, R. Caliandro, M. Camalli, B. Carrozzini, G. L. Cascarano, L. De Caro, C. Giacovazzo, G. Polidori, D. Siliqi and R. Spagna, J. Appl. Crystallogr., 2007, 40, 609-613.

18 G. Sheldrick, Acta Crystallogr., Sect. A: Found. Adv., 2015, 71, 3-8.

19 O. V. Dolomanov, L. J. Bourhis, R. J. Gildea, J. A. K. Howard and H. Puschmann, J. Appl. Crystallogr., 2009, 42, 339-341.

20 R. Ilmi, S. Kansız, N. Dege and M. S. Khan, J. Photochem. Photobiol., A, 2019, 377, 268-281.

21 T. Koizuka, M. Yamamoto, Y. Kitagawa, T. Nakanishi, K. Fushimi and Y. Hasegawa, Bull. Chem. Soc. Jpn., 2017, 90, 1287-1292.

22 (a) J. L. Hoard and J. V. Silverton, Inorg. Chem., 1963, 2, 235-242; (b) E. L. Muetterties and C. M. Wright, Q. Rev., Chem. Soc., 1967, 21, 109.

23 (a) K. L. Nash, R. D. Rogers, J. Ferraro and J. Zhang, Inorg. Chim. Acta, 1998, 269, 211-223; (b) U. Englert, B. Ganter, 
T. Wagner and W. Kläui, Z. Anorg. Allg. Chem., 1998, 624, 970-974.

24 (a) J. Huang, H.-M. Ding, Y. Xu, D. Zeng, H. Zhu, D.-M. Zang, S.-S. Bao, Y.-Q. Ma and L.-M. Zheng, Nat. Commun., 2017, 8, 2131;

(b) K. H. Zangana, E. M. Pineda and R. E. P. Winpenny, Dalton Trans., 2014, 43, 17101-17107.

25 M. Latva, H. Takalo, V. M. Mukkala, C. Matachescu, J. C. RodriguezUbis and J. Kankare, J. Lumin., 1997, 75, 149-169.

26 S. Sato and M. Wada, Bull. Chem. Soc. Jpn., 1970, 43, 1955-1962.

27 Y. Zheng, J. Lin, Y. Liang, Y. Yu, Y. Zhou, C. Guo, S. Wang and H. Zhang, J. Alloys Compd., 2002, 336, 114-118.
28 (a) R. Ilmi, A. Haque and M. S. Khan, J. Photochem. Photobiol., A, 2019, 370, 135-144; (b) R. Ilmi, S. Anjum, A. Haque and M. S. Khan, J. Photochem. Photobiol., A, 2019, 383, 111968.

29 C. Görller-Walrand and K. Binnemans, in Handbook on the Physics and Chemistry of Rare Earths, Elsevier, 1998, vol. 25, pp. 101-264.

30 S. Biju, M. L. P. Reddy, A. H. Cowley and K. V. Vasudevan, J. Mater. Chem., 2009, 19, 5179-5187.

31 (a) H. Xu, K. Yin and W. Huang, J. Phys. Chem. C, 2010, 114, 1674-1683; (b) H. Xu, K. Yin, L. Wang and W. Huang, Thin Solid Films, 2008, 516, 8487-8492. 